\title{
Neighborhood matters: high phylogenetic diversity of experimental plant assemblages improves community performance
}

\section{Rocío Chaves}

Rey Juan Carlos University

\section{Pablo Ferrandis}

Botanic Institute of the University of Castilla-La Mancha

\section{Adrián Escudero}

Rey Juan Carlos University

Arantzazu L. Luzuriaga ( $\square$ arantzazu.luzuriaga@urjc.es )

Rey Juan Carlos University

\section{Research Article}

Keywords: annual plants, coexistence, common community gardens, assembly mechanisms, drought, niche complementarity, phylogenetic diversity

Posted Date: April 28th, 2021

DOl: https://doi.org/10.21203/rs.3.rs-454800/v1

License: (a) (i) This work is licensed under a Creative Commons Attribution 4.0 International License. Read Full License 


\section{Abstract}

Background and Aims

Although the role played by phylogeny in the assembly of plant communities remains as a priority to complete the theory of species coexistence, experimental evidence is lacking. It is still unclear to what extent phylogenetic diversity is a driver or a consequence of species assembly processes. We experimentally explored how phylogenetic diversity can drive the community level responses to drought conditions in annual plant communities. To this end, we manipulated the phylogenetic diversity of the species assemblages and the water availability in a common garden experiment with two treatments: average natural rainfall and drought.

Methods

We recorded plant survival and the numbers of flowering and fruiting plants per species in each assemblage. High phylogenetic diversity favored species coexistence over time with higher plant survival and more flowering and fruiting plants, especially under severe drought.

Key Results

. Our results demonstrate the existence of niche complementarity and the convergence of water economy strategies as major mechanisms for promoting species coexistence in plant assemblages in semiarid Mediterranean habitats.

\section{Conclusions}

Our findings point to high phylogenetic diversity among neighboring plants as a plausible feature underpinning the recent "united we stand" framework, which states that diffuse positive interactions may promote mechanisms for the persistence of rare species in the community. We suggest that the large species number in the regional species pool may be the consequence of assembly processes occurring at small spatial scales, because the success of each species in terms of surviving and producing offspring was greater when the phylogenetic diversity was higher. Our study is a step forward to understand how phylogenetic relatedness is connected to the mechanisms determining the maintenance of biodiversity.

\section{Introduction}

The current theoretical framework and evidence suggest that both stochastic (Hubbel, 2001; Rosindell et al., 2012) and deterministic mechanisms (Diamond, 1975; Chase and Leibold, 2003; Götzenberger et al., 2012; HilleRisLambers et al., 2012; Adler et al., 2013) operate simultaneously on the assembly of plant communities (Lortie et al., 2004; Vellend et al., 2010, 2014; Escudero and Valladares 2016).

Environmental filters (abiotic and biotic) are the main drivers of species assembly and usually act hierarchically in semiarid systems (Luzuriaga et al., 2012). Plant trait-based community ecology is recognized as an invaluable tool for elucidating these processes because it provides morphological or 
physiological trait-based indices in order to identify the role played by each species at the community level in a niche complementarity context (Kraft et al., 2015). Thus, a species will become part of a realized species assemblage only if it possesses suitable traits to pass through the filters imposed by restrictive environmental conditions and it reduces niche overlap with neighbor species (Shipley, 2010).

In the last two decades, the toolbox of community ecologists has incorporated analyses of the phylogenetic patterns of plant communities to understand assembly processes (Webb et al., 2002; Pausas and Verdú, 2010). It is evident that historical and evolutionary mechanisms related to migration and speciation are critical for the formation of the regional species pool, but it is not clear how the phylogenetic diversity that describes the degree of relatedness among species can provide information about assembly processes that occur at the ecological time scale (Götzenberger et al., 2012; Gerhold et al., 2015). A phylogeny should summarize the ecological requirements of coexisting species because it synthesizes the morphological, physiological, and phenological changes in each species throughout evolutionary time in a reduced geographical domain (Kraft et al., 2007; Emerson and Gillespie, 2008; Cavender-Bares et al., 2009). However, phylogenetic distance among species could indicate not only niche differences, but also competitive inequalities (differences in species competitive abilities) which may drive competitive exclusion (Chesson 2000, Godoy et al.,2014). If functional traits are phylogenetically conserved, the phylogenetic diversity can serve as a good proxy of functional diversity (Kraft et al., 2007; Cadotte et al., 2013; Tucker et al.,2018), specially because many functional attributes may be hard or impossible to measure (Webb et al., 2002; Bello et al.,2017). Thus, phylogenetic diversity may represent the ecological differences in an assemblage better than the functional diversity itself (Cadotte et al.,2009; Srivastava et al., 2012; Cadotte et al.,2012; Staab et al.,2021; but see Mazel et al.,2018).

Many studies have aimed to detect assembly mechanisms based on the observed phylogenetic diversities under field conditions (i.e. phylogenetic response) (Webb et al., 2002; Kembel, 2009; Mayfield and Levine, 2010; Godoy et al., 2014; Luzuriaga et al. 2020), but the results are not completely coherent and they do not indicate unambiguous relationships among phylogenetic diversity and assembly processes (Kraft et al., 2007; Gerhold et al., 2015). For instance, coexistence of phylogenetically close species is usually interpreted as a result of habitat filtering processes and may be indicative of habitat use as a conserved trait along phylogeny (Webb et al., 2002; Valiente-Banuet and Verdú, 2007). However, these types of low phylogenetic diversity assemblages can also result from competition among species when the competitive ability under certain environmental conditions is associated with whole clades (Mayfield and Levine, 2010). By contrast, high phylogenetic diversity responses may be associated with facilitation among species (Valiente-Banuet and Verdú, 2007; Butterfield et al., 2013), but also with competition processes when competitive exclusion occurs between close relatives with patent niche overlap (Webb et al., 2002; Slinghsby and Verboom, 2006; Cahill et al., 2008). Furthermore, if functional convergence occurs among distantly related taxa, high phylogenetic diversity may also be observed in the resulting species assemblages under competitive scenarios (Cavender-Bares et al., 2004). 
Consequently, progress needs to be made in order to elucidate the causal relationships among phylogenetic diversity and assembly mechanisms by directly manipulating the phylogenetic diversity of whole assemblages (i.e., phylogenetic effect) together with the abiotic and biotic filtering conditions. This has rarely been attempted with vascular plants to the best of our knowledge (but see Feng et al. 2019; Galland et al.,2019). A wide consensus exists on the need for experimental approaches to specifically analyze the mechanisms involved in the assembly of plant communities (Götzenberger et al., 2012; HilleRisLambers et al., 2012). Ephemeral plant communities are especially appropriate for this type of experiments (Peralta et al. 2019) because of the rich regional species pool comprising around 100 annual plant species in the central Tagus valley (Luzuriaga et al., 2018), which naturally form high species density assemblages at fine spatial scales (up to 38 species per $0.25 \mathrm{~m}^{2}$ in rainy years; see Luzuriaga et al., 2012, 2015). In addition, the small size of individuals (average height $=10 \mathrm{~cm}$ ) and their short and synchronized life cycles (from autumn to spring) makes it feasible to manipulate the entire community and establish species assemblages of know phylogenetic structure. These features allow the design and implementation of experimental communities containing selected species under controlled conditions in common gardens (Peralta et al., 2019).

Shifts of assembly mechanisms in a regional species pool greatly depend on the harshness of the abiotic conditions (Pistón et al., 2015), especially dealing with resource availability (Luzuriaga et al., 2012; Matías et al., 2018). Since water availability is the main limiting resource in semi-arid Mediterranean ecosystems (Miranda et al., 2011), it strongly affects plant community dynamics (Chesson et al., 2004), particularly species richness and composition (Luzuriaga et al., 2012). Furthermore, species-specific interactions (i.e., competition and facilitation) that strongly determine species assemblages (e.g., Hart and Marshall, 2013) can shift depending on water availability (Armas and Pugnaire, 2011; Luzuriaga et al., 2012). In the present study, we manipulated both the level of phylogenetic relatedness among coexisting plants and the level of water stress in a common garden experiment by reproducing realistic annual plant assemblages along a period that encompasses a complete life cycle of annual plants (see Methods). The plant emergence of species in these communities is highly synchronized, so we prepared different phylogenetic combinations at this early demographic stage for our experimental treatments (i.e. phylogenetic effect). We aimed to evaluate the effects of the phylogenetic diversity of assemblages on surrogates of community performance under different water availability scenarios (i.e. stressful levels). In each experimental common garden unit, we measured the number of species and the total abundance of surviving plants each week for the whole phenological window of the community. In addition, we evaluated how many plants of each species achieved the reproductive (flowering) stage and how many set fruits. In the coexistence theory context (HilleRisLambers et al., 2012), community performance is the net sum of all the differences in fitness of the species that form an assemblage (Adler et al., 2007). The fitness inequalities among species may cause some of them to disappear, and thus the decrease in the number of species per sampling unit registered throughout the experiment indicated the limitations imposed by the experimental treatments. The proportion of individuals that produced flowers or fruits per experimental unit were used to represent the fitness inequalities among species. 
The two main hypotheses tested in this study are (see our conceptual framework in Fig. 1): (1) If phylogenetic relatedness at the beginning of the growing season predicts niche differences among species, then plants will coexist more readily in high phylogenetic diversity scenarios due to functional/niche complementarity. By contrast, if phylogenetic relatedness predicts the competitive ability of species, in the manner that closely related species can compete more efficiently for the same resources (Webb et al., 2002), then species will be more likely to coexist in low phylogenetic diversity scenarios. Previous studies have suggested that the competition among closely related species is symmetric, i.e. competition intensity between close relatives is very similar for both competitors (Scheffer and van Nes, 2006; Lamb and Cahill, 2008), and thus it does not cause exclusion, which may enhance the coexistence among similar competitor species (Yan et al., 2012). (2) Provided that the functional traits related to water economy are phylogenetically conserved, the effect of drought on the community and species level performance will be less intense in assemblages containing more resistant clades. Thus, in high diversity assemblages, a few species are expected to perform better than the rest, so the species richness will decline faster in these scenarios than in low phylogenetic diversity ones under severe drought treatments. By contrast, if the functional traits related to water economy are convergent among distantly related taxa, then we expect phylogenetically diverse assemblages to be more resistant to drought than those that are closely related.

\section{Materials And Methods}

The target plant community comprised annual plant communities on gypsum soils in the Tagus valley, central Spain, which has a semiarid Mediterranean climate with mean annual temperatures around $14.5^{\circ} \mathrm{C}$ and mean annual precipitation of $400 \mathrm{~mm} \mathrm{~m}^{-2} \mathrm{yr}^{-1}$. Precipitation events occur mainly in the late autumn and early spring, and there is an intense summer drought (Aranjuez weather station, $40^{\circ} 4^{\prime} 2^{\prime \prime} \mathrm{N}$; $3^{\circ} 32^{\prime} 46^{\prime \prime} \mathrm{W}, 540 \mathrm{~m}$ ). The dominant vegetation comprises gypsophilous dwarf shrubs (e.g., Lepidium subulatum L., Centaurea hyssopifolia Vahl, Gypsophila struthium L., Helianthemum squamatum (L.) Dum. Cours., Thymus lacaitae Pau, Herniaria fruticosa L., and Frankenia thymifolia Desf.) scattered in a matrix of bare soil covered mostly with a biological soil crust and seasonal cover of annual plants (over 120 species in the regional species pool in the middle Tagus valley; Luzuriaga et al., 2018). The annual plant community develops from the first autumn rainfall (October) until early summer (June) when seeds are set and subsequently dispersed.

From March to June during 2016 and 2017, we collected seeds from more than 40 individuals of 60 annual plant species that naturally co-occur in open areas in the field in three nearby locations (Aranjuez $\left(40^{\circ} 02^{\prime} 11.7^{\prime \prime} \mathrm{N}, 3^{\circ} 32^{\prime} 59.5^{\prime \prime} \mathrm{W} ; 591 \mathrm{~m}\right)$, Ciempozuelos $\left(40^{\circ} 08^{\prime} 36.9^{\prime \prime} \mathrm{N}, 3^{\circ} 37^{\prime} 00.0^{\prime \prime} \mathrm{W} ; 585 \mathrm{~m}\right)$, and Portalrubio de Guadamejud (4017'34.4"N, $\left.2^{\circ} 35^{\prime} 31.0^{\prime \prime} \mathrm{W} ; 755 \mathrm{~m}\right)$. Seeds were cleaned and submitted to a light hot thermal shock $\left(15\right.$ days at $\left.50^{\circ} \mathrm{C}\right)$ to simulate hot summer conditions to break the seed dormancy. We established 6 experimental scenarios, but we finally maintained 4 of them because two of the scenarios did not fulfill the requirements to enter the experiment (seed germination was not enough at each plot), 
thus, we finally used 28 species to build the species assemblages (see below). We prepared a common garden experiment with 110 experimental assemblages and more than 7000 seedlings.

The experimental design consisted of manipulating the phylogenetic diversity of starting experimental assemblages together with water availability treatments. In order to select the high and low phylogenetic diversity scenarios, we calculated the phylogenetic species variability (PSV) index (Helmus et al., 2007) and the Net Relatedness Index (NRI) index (Webb 2000). The PSV index indicates the degree of relatedness among different species in a community with values ranging from 0 to 1 . It has low values when the species that form the assembly are closely related. The NRI is a standardized phylogenetic index that contrasts the observed MPD (Mean Pairwise Distance) to 1000 null models. The more positive $\mathrm{NRI}$ values indicate that species are close in the phylogenetic tree and the more negative NRI values that species are more dispersed in the phylogenetic tree (Appendix 1). Values for high phylogenetic diversity scenarios (PSV $=0.82$ and 0.85 ; NRI $=-0.53$ and -0.17 ) were decided on the basis of those naturally observed in the field at this stage (PSV 0.8; data from Luzuriaga et al., 2012), while values for low diversity assemblages were experimentally diminished by choosing related species of the family Asteraceae (PSV $=0.24 ; \mathrm{NRI}=9.6 ; \mathrm{p}<0.001$ ) and species of the orders Brassicales and Malvales (PSV = $0.64 ; \mathrm{NRI}=2.5 ; \mathrm{p}<0.05$ ). These indices were calculated running the R packages "ape" (Paradis and Schliep, 2018) and "picante" (Kembel et al., 2010) based on the phylogenetic tree for the 28 species involved in the experiment built using "V.Phylomaker" package, using phylo.maker function and the "scenario1" option to bind new tips (Jin and Qian, 2019) (Appendix 2). To control for the idiosyncratic effect of species identities, we established two different species combinations for each phylogenetic diversity level. Thus, four taxonomic combinations were constructed comprising two combinations of distantly related species (high phylogenetic diversity scenarios) and two of more closely related species (low phylogenetic diversity scenarios).

We established water availability treatments with two levels in a fully crossed factorial design: average precipitation $v s$. drought. The average precipitation treatment simulated the monthly average rainfall recorded between 1981 and 2010 in the study area, and the drought treatment used 33\% of the average rainfall for each month. We established two phylogenetic diversity levels · two taxonomic combinations of species · two water availability treatments (eight experimental scenarios). Each scenario was replicated in 10 to 16 units, thereby resulting in 110 experimental assemblages.

A common garden experiment was conducted in a greenhouse at Rey Juan Carlos University (https://urjccultive.webnode.es/ Móstoles, Madrid, Spain: $40^{\circ} 20^{\prime} 2^{\prime \prime} \mathrm{N}, 3^{\circ} 52^{\prime} 00^{\prime \prime} \mathrm{W}, 650 \mathrm{~m}$ ) from October 2017 when the seeds were sown, until June 2018 when the last individuals were collected. We used round pots with a diameter of $30 \mathrm{~cm}$ and height of $10 \mathrm{~cm}$, which were filled with seed-free gypsum soil from a gypsum quarry located close to the collection sites. We aimed to establish 10 plants of each seven coexisting species per pot, so we initially sowed 70 seeds per species in each one. Excess of emergent seedlings was periodically removed to ensure the planned abundance of species. We watered pots to the soil watercarrying capacity for the first 20 weeks to ensure the establishment of experimental assemblages at the emergence stage mimicking natural field conditions and then commenced the water availability 
treatments, which were maintained for 19 weeks. Between February and June, we monitored plant survival per species and per pot (summing 7700 plants) every two weeks, and we recorded the numbers of flowering plants once a week. In addition, for each species and pot we registered the final number of plants that reached the fruiting stage.

Generalized linear models were employed to analyze species richness, plant survival and the numbers of flowering and fruiting plants per pot. We do not use generalized linear mixed models because the term "pot", as a random factor, explained extremely tiny fractions of the variability (var $<0.008$ and SD $<0.09$, in all cases), so we decided to remove it out of the models. The water availability and phylogenetic diversity were treated as fixed factors in all variables and time as a fixed covariate in species richness, plant survival and the number of flowering plants. We used the Poisson distribution as the error distribution function and the logarithmic link function in all models. Generalized linear models were generated using the "glm" function in the "stats" package in R (4.0.3 version) (R Core Team, 2020).

\section{Results}

Phylogenetically more diverse assemblages favored species coexistence, especially under stressful environmental conditions (Table 1; Figs. 2 and 3). In particular, we found that the experimental assemblages formed of distantly related species exhibited higher survival at the plant level but also at the species level (i.e., species richness per pot) compared with assemblages with closely related species. This trend was exacerbated under dry experimental conditions where more plants flowered and fructified in distantly related assemblages compared with those that were closely related (Figs. 2 and 3). In addition, high phylogenetic diversity scenarios showed earlier flowering times both in control and drought conditions than low diversity ones. Thus, the experimental assemblages with high phylogenetic diversity were less sensitive to drought than the low phylogenetic diversity assemblages in terms of the plant survival, number of coexisting species, and numbers of flowering and fruiting plants in each experimental unit. 
Table 1

Generalized linear models (GLMs) for the analyses of the numbers of species, surviving plants and flowering plants per pot and per sampling date, and for the number of fruiting plants per pot. Sampling date was used as a fixed covariate in the first three models to statistically control for the effect of time (it was always highly significant, not shown). We did not consider the sampling date to model the number of fruiting plants because this variable was not measured over time, it was just the total cumulative number of fruiting plants per species in each pot. Phylogenetic diversity (PD) and water availability (W) were used as fixed factors. We used the Poisson distribution as the error distribution function and the logarithmic link function in all models. Chi-square values are indicated.*: $p<0.05 ; * *: p<0.01 ; * \star \star *: p<0.001$.

\begin{tabular}{|lllll|}
\hline & $\begin{array}{c}\text { Species } \\
\text { richness }\end{array}$ & Surviving plants & Flowering plants & Fruiting plants \\
\hline Phylogenetic diversity (PD) & $11.65^{\star \star \star}$ & $131.7^{\star \star \star}$ & $328.2^{\star \star \star}$ & $6.85^{\star \star}$ \\
\hline Water availability (W) & $23.93^{\star \star *}$ & $315.4^{\star \star \star}$ & $789.6^{\star \star *}$ & $371.4^{\star \star \star}$ \\
\hline PD $\cdot$ W & 2.1 & $35.5^{\star \star *}$ & $135.0^{\star \star *}$ & $28.6 \star \star \star$ \\
\hline
\end{tabular}

\section{Discussion}

As hypothesized phylogenetic relatedness among coexisting plants drives community level processes such as survival and reproduction. In particular, we found that assemblages formed of more distantly related species favored plant survival and consequently species coexistence, as shown by the reduced decay of the species richness throughout the whole life cycle of the annual plant experimental assemblages. Even more, plants not only were able to survive more successfully in phylogenetically diverse assemblages, but also more individuals completed the reproductive stage by setting flowers and fruits. In addition, we demonstrated the higher resistance of phylogenetically diverse assemblages to drought in terms of plant survival, number of coexisting species over time, and numbers of flowering and fruiting plants per species in the realized assemblages, which supports the hypothesis that phylogenetic relatedness predicts niche differences between species (Hypothesis 1a in Fig. 1).

Our results can also be interpreted in terms of species niche complementarity (Chase and Leibold, 2003; Silvertown, 2004), which predicts that species with differences in terms of their resource use are more likely to coexist due to the reduced competitiveness among them (Pacala and Tilman, 1994; Chesson, 2000; Silvertown, 2004; Holt, 2008). Distantly related species are more likely to be phenologically and functionally complementary, and thus to suffer less from the effects of competition compared to living among conspecifics or close relatives in the neighborhood (Tilman et al., 2001; Verdú et al., 2009; Valiente-Banuet and Verdú, 2013). Closely related species are likely to have ecologically similar requirements (Lord et al., 1995; Wiens and Graham, 2005), so they would share fundamental niches and be more prone to compete strongly for resources. Several mechanisms may promote niche complementarity, such as phenological differences among species (Pfennig and Murphy, 2002; Ashton et al., 2010), different resource use traits (D'Antonio and Mahall, 1991; Jumpponen et al., 2002; Miller et al., 2007), or different root foraging activities (de Kroon and Mommer, 2006). Maynard et al. (2019) found that phenological differences among the species in a community could affect the competitive dynamics 
to promote coexistence, thereby possibly leading to an increase in species richness at fine spatial scales, which may promote stabilizing dynamics. In our study, the distantly related species probably differed in terms of their phenology, resource uptake, and physiological efficiency, which could have reduced the intensity of the competitive interactions among them (Kraft et al., 2015). This situation could have promoted individual plant survival and species richness, as well as higher plant fitness in high phylogenetic diversity assemblages (see also Violle et al., 2011).

Remarkably, the beneficial effect of high phylogenetic diversity on community level performance was enhanced under severe drought, in terms of overall plant survival, coexisting species richness, as well as number of flowering and fruiting plants per experimental unit. This result supports the idea that drought resistance is a convergent strategy along phylogeny of annual plant species in our study system (Hypothesis 2b in Fig. 1). Our results also agree with García-Camacho et al. (2017) who did not detect phylogenetic conservation in terms of the rainfall preferences of 111 annual plant species from an aridity gradient in Israel. Thus, the annual plant species in dryland areas have evolved over a long period under strong pressure due to drought events and highly unpredictable rainfall events, which may have resulted in the convergent adaptation of distantly related phylogenetic clades to cope with limiting water conditions. Clearly, a powerful abiotic filter such as severe droughts could have shaped the regional species pool over an evolutionary time scale. Consequently, regardless of phylogenetic relatedness, all the species in the community would be able to cope with water limitation, including when it occurs over an ecological time scale (Vellend, 2016).

Assembly processes that occur at the community level may affect the evolution of species over the long term (see also Cavender-Bares et al., 2009; McPeek, 2017; terHorst et al., 2018). Coexistence among closely related species can trigger character displacement to reduce competition intensity (Dayan and Simberloff, 2005) or character convergence to reduce competition asymmetry (Scheffer and van Nes, 2006). Community processes seem to exert crucial effects on evolution (McPeek, 2017), and provide a plausible explanation for the intriguing question regarding how so many annual plant species can coexist in the harsh conditions of semiarid gypsum systems. We suggest that the high species richness found at the regional scale (more than 120 annual species; Luzuriaga et al., 2018) may be the consequence of assembly processes occurring at small spatial scales in a type of feedback process because the success of each species in terms of surviving and offspring production was greater when the phylogenetic diversity was higher. In this line, our findings may support the "united we stand" framework (Calatayud et al., 2020), which states that rare species might remain in assemblages by establishing diffuse positive interactions. Such "diffuse positive interactions" could be related to high phylogenetic diversity among neighboring plants at fine spatial scales (see Chacón-Labella et al. 2016).

In conclusion, our results strongly demonstrate the existence of niche complementarity and the evolutionary convergence of water economy strategies as major mechanisms for organizing annual plant assemblages in semiarid Mediterranean gypsum habitats. Species that grow in assemblages of distantly related species are more likely to survive and fructify than those that grow in closely related ones. Importantly, we showed that this effect was exacerbated in drought conditions. Intense droughts occur 
often in semiarid Mediterranean ecosystems (Miranda et al., 2011; Luzuriaga et al., 2012) and their intensity is expected to increase in the future (IPCC, 2014). Furthermore, the United Nations recently declared the next decade as "The Decade on Ecosystem Restoration" (United Nations Environment Programme, 2019), and they remarked the importance of understanding the drivers of community assembly. In this context, our study is timely since restoration strategies are moving beyond traditional restoration actions and adopting new tools that better describe the characteristics of species assemblies. In this way, we demonstrate that phylogenetic diversity is an excellent measure that can be used to understand species assembly processes. Furthermore, our study highlights that experimental approaches can provide new answers to old questions in community ecology by connecting assembly processes and patterns in a more robust causal framework. In particular, we show that species rich annual plant communities are excellent model systems for such investigations, due to the feasibility of manipulating species assemblages and the short time lapses needed to account for a complete generation.

\section{Declarations}

Author contributions: $A E$ and $A L$ conceived the idea; $A L, R C$ and PF collected seeds for the experimental set-up; $A L$ and RC designed methodology; RC collected the data; RC and AL analysed the data; $A L$ and RC led the writing of the manuscript. All authors contributed critically to the drafts and gave final approval for publication.

\section{Ethical statement}

Authors assure that legislation on seed collection has been accomplished.

Permission obtained from responsible authority to collect seeds.

\section{Acknowledgments}

We thank Carlos Díaz and José Margalet for experiment assistance. Roberto López Rubio for his help with the experimental setup. We thank the Spanish Meteorological Agency (AEMET) for providing climatic data. Rocío Chaves was supported by two predoctoral contracts (PEJD-2016/AMB-2142; PEJD-2018PRE/AMB-8927) from the Madrid Regional Government and European Youth Employment Initiative of the European Commission. Financial support was also provided by the AGORA project (CGL2016-77417-P Spanish Government), REMEDINAL project (TE-CM S2018/EMT-4338 - Madrid Regional Government), and GYPWORLD project (H2020-MSCA-RISE-2017-777803 - European Commission). Gypsum soil was provided from Yesos Ibéricos-Algiss.

\section{References}

Adler PB, Fajardo A, Kleinhesselink AR, Kraft NJB. 2013. Trait-based tests of coexistence mechanisms. Ecology Letters 16: 1294-1306. 
Adler PB, HilleRisLambers J, Levine JM. 2007. A niche for neutrality. Ecology Letters 10: 95-104.

Armas C, Pugnaire FI. 2011. Belowground zone of influence in a tussock grass species. Acta Oecologica 37: 284-289.

Ashton IW, Miller AE, Bowman WD, Suding KN. 2010. Niche complementarity due to plasticity in resource use: plant partitioning of chemical $\mathrm{N}$ forms. Ecology 91: 3252-3260.

Butterfield BJ et al. 2013. Alpine cushion plants inhibit the loss of phylogenetic diversity in severe environments. Ecology Letters 16: 478-486.

Cadotte MW, Albert CH, Walker SC. 2013. The Ecology of differences: assessing community assembly with trait and evolutionary distances. Ecology Letters 16: 1234-1244.

Cadotte MW, Cavender-Bares J, Tilman D, Oakley TH. 2009. Using Phylogenetic, Functional and Trait Diversity to Understand Patterns of Plant Community Productivity. PLoS ONE 4(5): e5695.

Cadotte MW, Dinnage R, Tilman D. 2012. Phylogenetic diversity promotes ecosystem stability. Ecology 93: S223-S233.

Cahill JF, Kembel SW, Lamb EG, Keddy PA. 2008. Does phylogenetic relatedness influence the strength of competition among vascular plants? Perspectives inPlant Ecology Evolution and Systematics 10: 41-50.

Calatayud J. et al. 2020. Positive associations among rare species and their persistence in ecological assemblages. NatureEcology and Evolution 4: 40-45.

Cavender-Bares J, Ackerly DD, Baum DA, Bazzaz FA. 2004. Phylogenetic overdispersion in Floridian oak communities. The American Naturalist 163: 823-843.

Cavender-Bares J, Kozak KH, Fine PV, Kembel SW. 2009. The merging of community Ecology and phylogenetic biology. Ecology Letters 12: 693-715.

Chacón-Labella J, de la Cruz M, Escudero A. 2016. Beyond the classical nurse species effect: diversity assembly in a Mediterranean semi-arid dwarf shrubland. Journal of Vegetation Science, 27: 80-88.

Chase JM, Leibold MA. 2003. Ecological Niches: Linking Classical And Contemporary Approaches (University of Chicago Press).

Chesson P. 2000. Mechanisms of maintenance of species diversity. Annual Review of Ecology and Systematics 31: 343-366.

Chesson P. et al. 2004. Resource pulses, species interactions, and diversity maintenance in arid and semi-arid environments. Oecologia 141: 236-253. 
D'Antonio CM, Mahall BE. 1991. Root profiles and competition between the invasive, exotic perennial, Carpobrotus edulis, and two native shrub species in California coastal scrub. American Journal of Botany 78: 885-894.

Dayan T, Simberloff D. 2005. Ecological and community-wide character displacement: the next generation. Ecology Letters 8: 875-894.

de Bello F, Smilauer P, Diniz JAF, Carmona CP, Lososova Z, Herben T, and Gotzenberger L. 2017. Decoupling phylogenetic and functional diversity to reveal hidden signals in community assembly. Methods in Ecology and Evolution 8: 1200-1211.

de Kroon H, Mommer L. 2006. Root foraging theory put to the test. Trends in Ecology and Evolution 21: 113-116.

Diamond JM. 1975. Assembly of species communities. In M. L. Cody, and J. M. Diamond (Eds.), Ecology and evolution of communities (pp. 342- 444). (Cambridge, MA: Harvard University Press 1975)

Emerson BC, Gillespie RG. 2008. Phylogenetic analysis of community assembly and structure over space and time. Trends in Ecology and Evolution 23: 619-630.

Escudero A, Valladares F. 2016. Trait-based plant Ecology: Moving towards a unifying species coexistence theory: Features of the special section. Oecologia 180: 919-922.

Feng Y, Fouqueray TD, van Kleunen M. 2019. Linking Darwin's naturalisation hypothesis and Elton's diversity-invasibility hypothesis in experimental grassland communities. Journal of Ecology 107:794805.

Galland T, Adeux G, Dvořáková H, et al. 2019. Colonization resistance and establishment success along gradients of functional and phylogenetic diversity in experimental plant communities. Journal of Ecology 107: $2090-2104$.

García-Camacho R, Metz J, Bilton MC, Tielbörger K. 2017. Phylogenetic structure of annual plant communities along an aridity gradient. Interacting effects of habitat filtering and shifting plant-plant interactions. Israel Journal of Plant Sciences 64: 122-134.

Gerhold P, Cahill JF, Winter M, Bartish IV, Prinzing A. 2015. Phylogenetic patterns are not proxies of community assembly mechanisms (they are far better). Functional Ecology 29: 600-614.

Godoy O, Kraft NJ, Levine JM. 2014. Phylogenetic relatedness and the determinants of competitive outcomes. Ecology Letters 17: 836-844.

Götzenberger L. et al. 2012. Ecological assembly rules in plant communities--approaches, patterns and prospects. Biological Reviews of the Cambridge Philosophical Society 87: 111-127. 
Hart SP, Marshall DJ. 2013. Environmental stress, facilitation, competition, and coexistence. Ecology 94: 2719-2731.

Helmus MR, Savage K, Diebel MW, Maxted JT, Ives AR. 2007. Separating the determinants of phylogenetic community structure. Ecology Letters 10: 917-925.

HilleRisLambers J, Adler PB, Harpole WS, Levine JM, Mayfield MM. 2012. Rethinking Community Assembly through the Lens of Coexistence Theory. Annual Review of Ecology, Evolution, and Systematics 43: 227-248.

Holt RD. 2008. Theoretical perspectives on resource pulses. Ecology 89: 671-681.

Hubbel SP. 2001. The Unified Neutral Theory Of Biodiversity And Biogeography (Princeton).

IPCC 2014: Climate Change 2014: Synthesis Report. Contribution of Working Groups I, II and III to the Fifth Assessment Report of the Intergovernmental Panel on Climate Change [Core Writing Team, R.K. Pachauri and L.A. Meyer (eds.)]. IPCC, Geneva, Switzerland, 151 pp.

Jin Y, Qian HV. 2019. PhyloMaker: an R package that can generate very large phylogenies for vascular plants. Ecography 42: 1353-1359.

Jumpponen A, Högberg P, Huss-Danell K, Mulder CPH. 2002. Interspecific and spatial differences in nitrogen uptake in monocultures and two-species mixtures in north European grasslands. Functional Ecology 16: 454-461.

Kembel SW. 2009. Disentangling niche and neutral influences on community assembly: assessing the performance of community phylogenetic structure tests. Ecology Letters 12: 949-960.

Kembel SW. et al. 2010. Picante: R tools for integrating phylogenies and Ecology. Bioinformatics 26: 1463-1464.

Kraft NJ, Godoy O, Levine JM. 2015. Plant functional traits and the multidimensional Nature of species coexistence. Proceedings of the National Academy of Sciences 112: 797-802.

Kraft NJB, Cornwell WK, Webb CO, Ackerly D. 2007. Trait Evolution, Community Assembly, and the Phylogenetic Structure of Ecological Communities. The American Naturalist 170: 271-283.

Lamb EG, Cahill Jr JF. 2008. When competition does not matter: grassland diversity and community composition. The American Naturalist 17: 777-787.

Lord J, Westoby M, Leishman M. 1995. Seed size and phylogeny in six temperate floras: constraints, niche conservatism, and adaptation. The American Naturalist 146: 349-364.

Lortie CJ. et al.2004. Rethinking plant community theory. Oikos 107: 433-438. 
Luzuriaga AL, Ferrandis P, Flores J, Escudero A. 2020. Effect of aridity on species assembly in gypsum drylands: a response mediated by the soil affinity of species. AOB PLANTS12: plaa020.

Luzuriaga AL, González JM, Escudero A. 2015. Annual plant community assembly in edaphically heterogeneous environments. Journal of Vegetation Science 26: 866-875.

Luzuriaga AL, Sánchez AM, López-Angulo J, Escudero A. 2018. Habitat fragmentation determines diversity of annual plant communities at landscape and fine spatial scales. Basic and AppliedEcology 29: 12-19.

Luzuriaga AL, Sánchez AM, Maestre FT, Escudero A. 2012. Assemblage of a semi-arid annual plant community: abiotic and biotic filters act hierarchically. PLOS ONE 7: 1-9.

Matías L, Godoy O, Gómez-Aparicio L, Pérez-Ramos IM. 2018. An experimental extreme drought reduces the likelihood of species to coexist despite increasing intransitivity in competitive networks. Journal of Ecology 106: 826-837.

Mayfield MM, Levine JM. 2010. Opposing effects of competitive exclusion on the phylogenetic structure of communities. Ecology Letters 13: 1085-1093.

Maynard DS, Serván CA, Capitán JA, Allesina S. 2019. Phenotypic variability promotes diversity and stability in competitive communities. Ecology Letters 22: 1776-1786.

Mazel F, Pennell MW, Cadotte MW, Diaz S, Dalla Riva GV, et al.,2018.Prioritizing phylogenetic diversity captures functional diversity unreliably. Nature Communications 9: 2888.

McPeek MA. 2017. Evolutionary community ecology. Princeton, NJ: Princeton Univ. Press.

Miller AE, Bowman WD, Suding KN. 2007. Plant uptake of inorganic and organic nitrogen: neighbor identity matters. Ecology 88: 1832-1840.

Miranda JD, Armas C, Padilla FM, Pugnaire Fl. 2011. Climatic change and rainfall patterns: Effects on semi-arid plant communities of the Iberian Southeast. Journal of Arid Environments 75: 1302-1309.

Pacala SW, Tilman D. 1994. Limiting similarity in mechanistic and spatial models of plant competition in heterogeneous environments. The American Naturalist 143: 222-257.

Paradis E, Schliep K. 2018. ape 5.0: an environment for modern phylogenetics and evolutionary analyses in R. Bioinformatics 35: 526-528.

Pausas JG, Verdú M. 2010. The jungle of methods for evaluating phenotypic and phylogenetic structure of communities. BioScience, 60: 614-625.

Peralta AM, Sánchez AM, Luzuriaga AL, de Bello F, Escudero A. 2019. Evidence of functional species sorting by rainfall and biotic interactions: A community monolith experimental approach. Journal of 
Ecology 107: 2772-2788.

Pfennig DW, Murphy PJ. 2002. How fluctuating competition and phenotypic plasticity mediate species divergence. Evolution 56: 1217-1228.

Pistón N, Armas C, Schöb C, Macek P, Pugnaire Fl. 2015. Phylogenetic distance among beneficiary species in a cushion plant species explains interaction outcome. Oikos 124: 1354-1359.

Rosindell J, Hubbell SP, He F, Harmon LJ, Etienne RS. 2012. The case for ecological neutral theory. Trends in Ecology and evolution 27: 203-208.

Scheffer M, van Nes EH. 2006. Self-organized similarity, the evolutionary emergence of groups of similar species. Proceedings of the National Academy of Sciences 103: 6230-6235.

Shipley B. 2010. From Plant Traits To Vegetation Structure: Chance And Selection In The Assembly Of Ecological Communities (Cambridge University Press).

Silvertown J. 2004. Plant coexistence and the niche. Trends in Ecology and Evolution 19: 605-611.

Slingsby JA, Verboom GA. 2006. Phylogenetic relatedness limits co-occurrence at fine spatial scales: evidence from the schoenoid sedges (Cyperaceae: Schoeneae) of the Cape Floristic Region, South Africa. The American Naturalist 168: 14-27.

Srivastava DS, Cadotte MW, MacDonald AAM, Marushia RG, Mirotchnick N. 2012. Phylogenetic diversity and the functioning of ecosystems. Ecology Letters 15: 637-648.

Staab M, Liu X, Assmann T, et al. 2021. Tree phylogenetic diversity structures multitrophic communities. Functional Ecology 35: 521-534.

terHorst CP, Zee PC, Heath KD et al. 2018. Evolution in a community context: Trait responses to multiple species interactions. American Naturalist 191: 368-380.

Tilman D. et al. 2001. Diversity and productivity in a long-term grassland experiment. Science 294: 843845.

Tucker CM, Davies TJ, Cadotte MW, Pearse WD. 2018. On the relationship between phylogenetic diversity and trait diversity. Ecology 99: 1473-1479.

Valiente-Banuet A, Verdu M. 2007. Facilitation can increase the phylogenetic diversity of plant communities. Ecology Letters10: 1029-1036.

Valiente-Banuet A, Verdu M. 2013. Plant facilitation and phylogenetics. Annual Review of Ecology, Evolution, and Systematics 44: 347-366. 
Vellend M. 2010. Conceptual synthesis in community Ecology. The Quarterly Review of Biology 85: 183206.

Vellend M. 2016. The Theory Of Ecological Communities (Princeton University Press).

Vellend M. et al. 2014. Assessing the relative importance of neutral stochasticity in ecological communities. Oikos 123: 1420-1430.

Verdu M, Rey PJ, Alcantara JM, Siles G, Valiente-Banuet A. 2009. Phylogenetic sigNatures of facilitation and competition in successional communities. Journal of Ecology 97: 1171-1180.

Violle C, Nemergut DR, Pu Z, Jiang L. 2011. Phylogenetic limiting similarity and competitive exclusion. Ecology Letters 14: 782-787.

Webb CO, Ackerly DD, McPeek MA, Donoghue MJ. 2002. Phylogenies and Community Ecology. Annual Review of Ecology and Systematics 33: 475-505.

Webb CO. 2000. Exploring the phylogenetic structure of ecological communities: an example for rain forest trees. The American Naturalist 156: 145-155.

Wiens JJ, Graham CH. 2005. Niche conservatism: integrating evolution, Ecology, and conservation biology. Annual Review of Ecology Evolution and Systematics 36: 519-539.

Yan BG, Zhang J, Liu Y, Li ZB, Huang X, Yang WQ. et al. 2012 Trait assembly of woody plants in communities across sub-alpine gradients: identifying the role of limiting similarity. Journal of Vegetation Science 23: 698- 708.

\section{Figures}




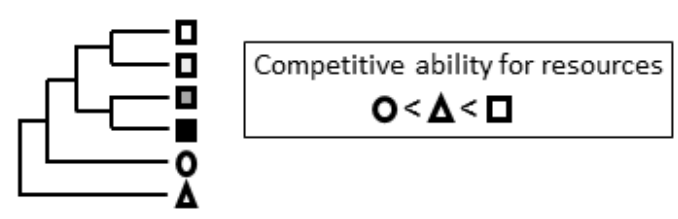

1a) Phylogeny predicts niche overlap

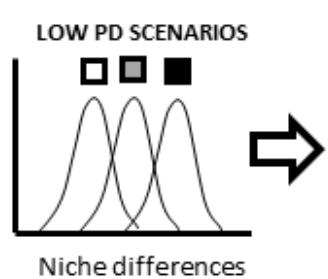

HIGH PD SCENARIOS

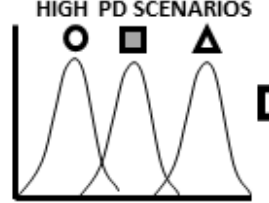

Niche differences
LOW PD SCENARIOS

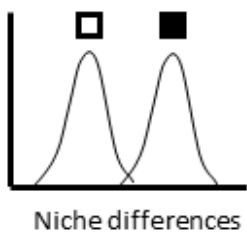

HIGH PD SCENARIOS

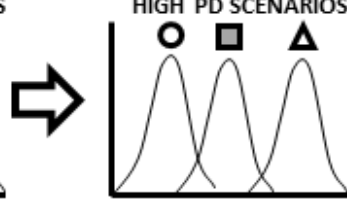

Niche differences

2a) Resistance to drought conserved in phylogeny

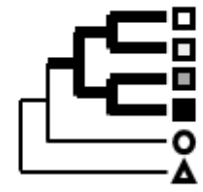

LOW PD SCENARIOS

LOW PD SCENARIOS

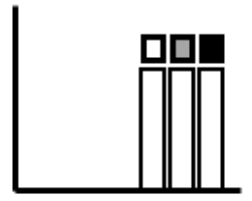

Resistance to drought

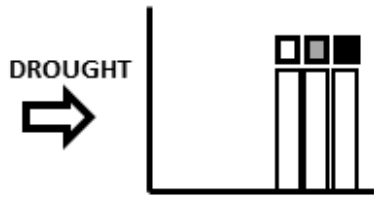

Resistance to drought

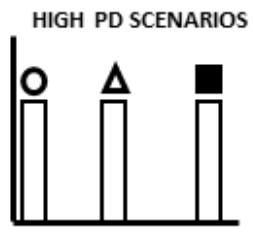

Resistance to drought

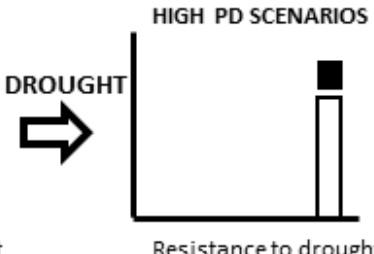

Resistance to drought 1b) Phylogeny predicts competitive ability for resources

LOW PD SCENARIOS LOW PD SCENARIOS

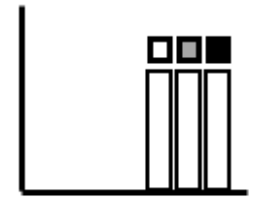

Competitive ability

HIGH PD SCENARIOS

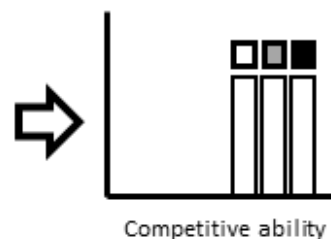

HIGH PD SCENARIOS

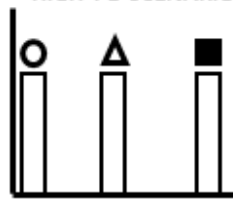

Competitive ability

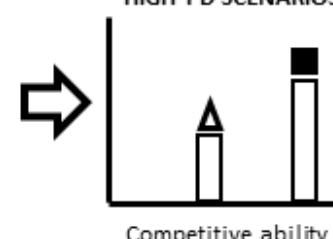

Competitive ability

2b) Resistance to drought convergent across phylogeny

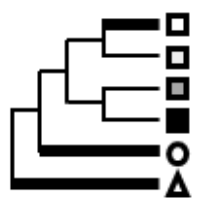

LOW PD SCENARIOS LOW PD SCENARIOS

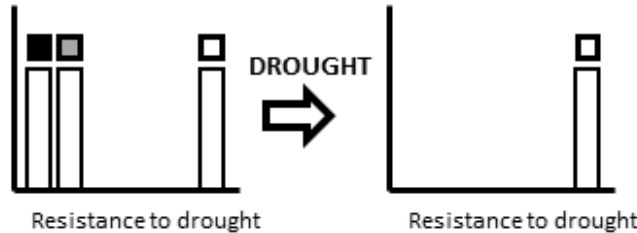

HIGH PD SCENARIOS HIGH PD SCENARIOS

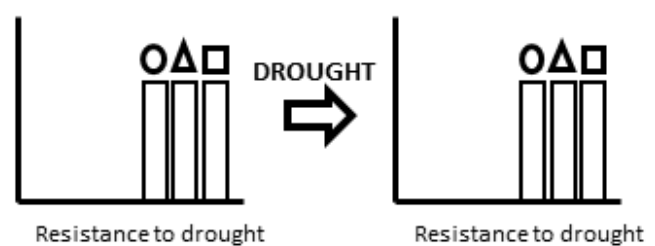

Figure 1

Conceptual model illustrating the hypotheses on the mechanisms involved in the assembly of the annual plant community related to phylogenetic diversity. (1) If phylogenetic relatedness predicts the intensity of niche overlap-differentiation among species, then plants will coexist more readily in high phylogenetic diversity scenarios due to functional/niche complementarity. Conversely, if phylogenetic relatedness predicts the competitive ability of species, then coexistence will be more likely to occur in low 
phylogenetic diversity scenarios (i.e., competition symmetry will enhance the coexistence among similar competitors). (2) If functional traits related to water economy are phylogenetically conserved, the response of plants to drought would be more heterogeneous in high diversity assemblages, resulting in a faster decline of species richness. In contrast, if water economy traits in the species pool are convergent among distantly related taxa, phylogenetically diverse assemblages will be more resistant to drought than those formed by close relatives.

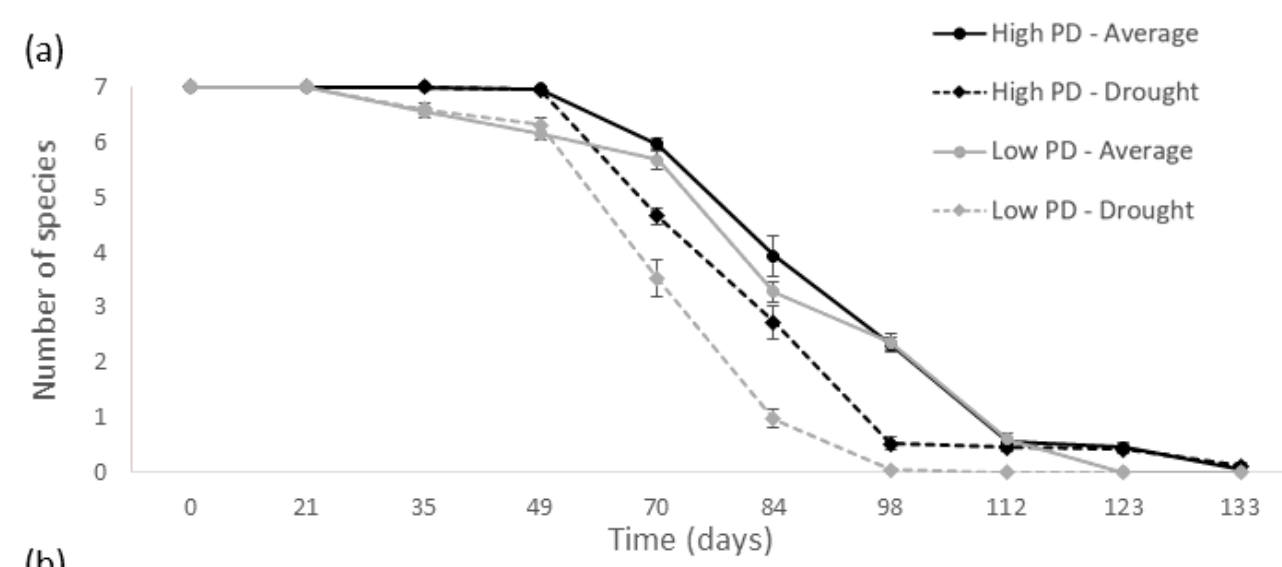

(b)
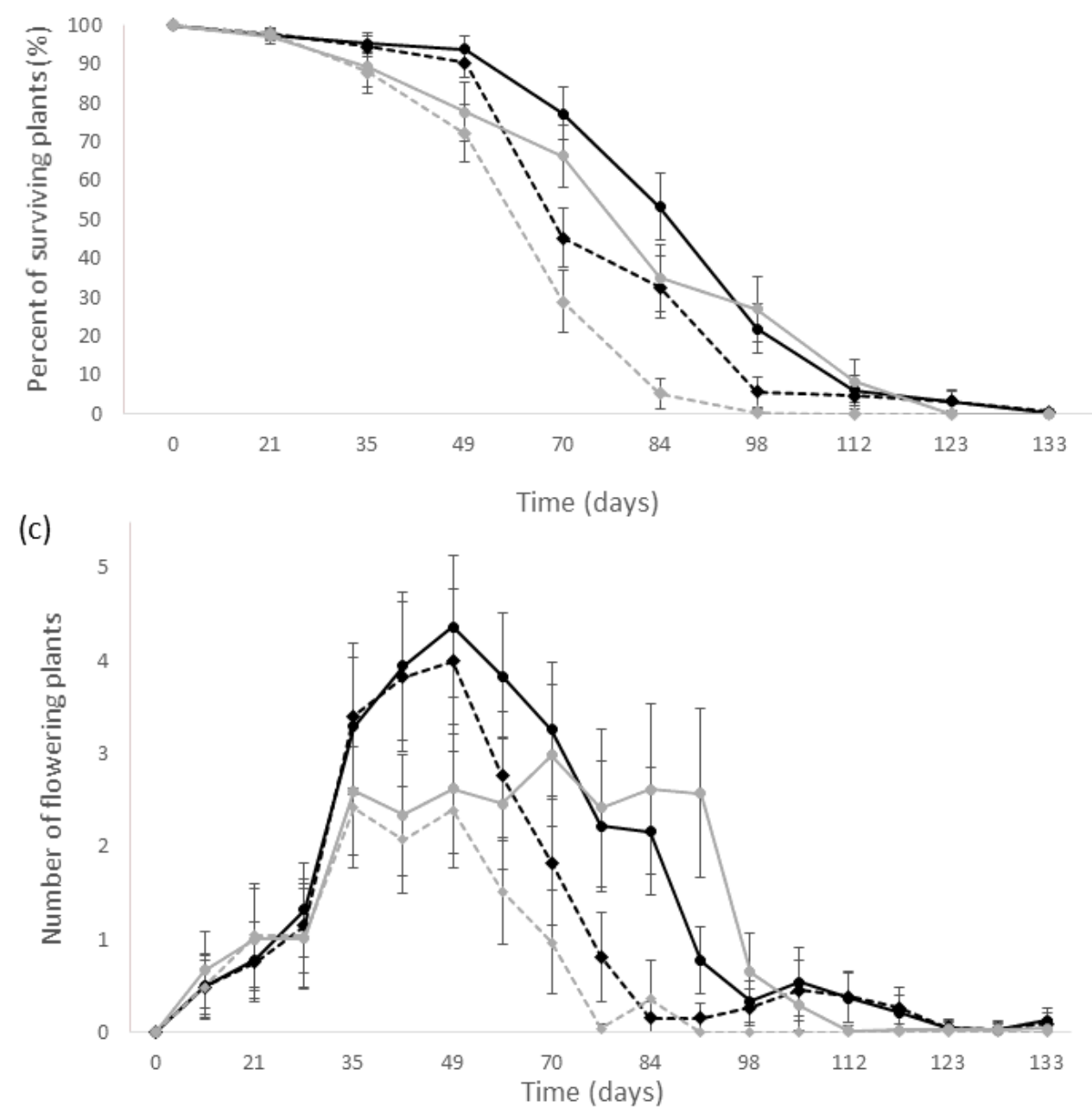

Figure 2 
(a) Number of species, (b) number of surviving plants and (c) number of flowering plants, per pot on each sampling date. Black lines represent high phylogenetic diversity (PD) scenarios and grey lines denote low phylogenetic diversity scenarios. Solid lines represent the average precipitation treatments based on natural precipitation for 30 years, and spotted lines denote drought treatments (33\% of the average precipitation). Vertical bars represent the standard error.

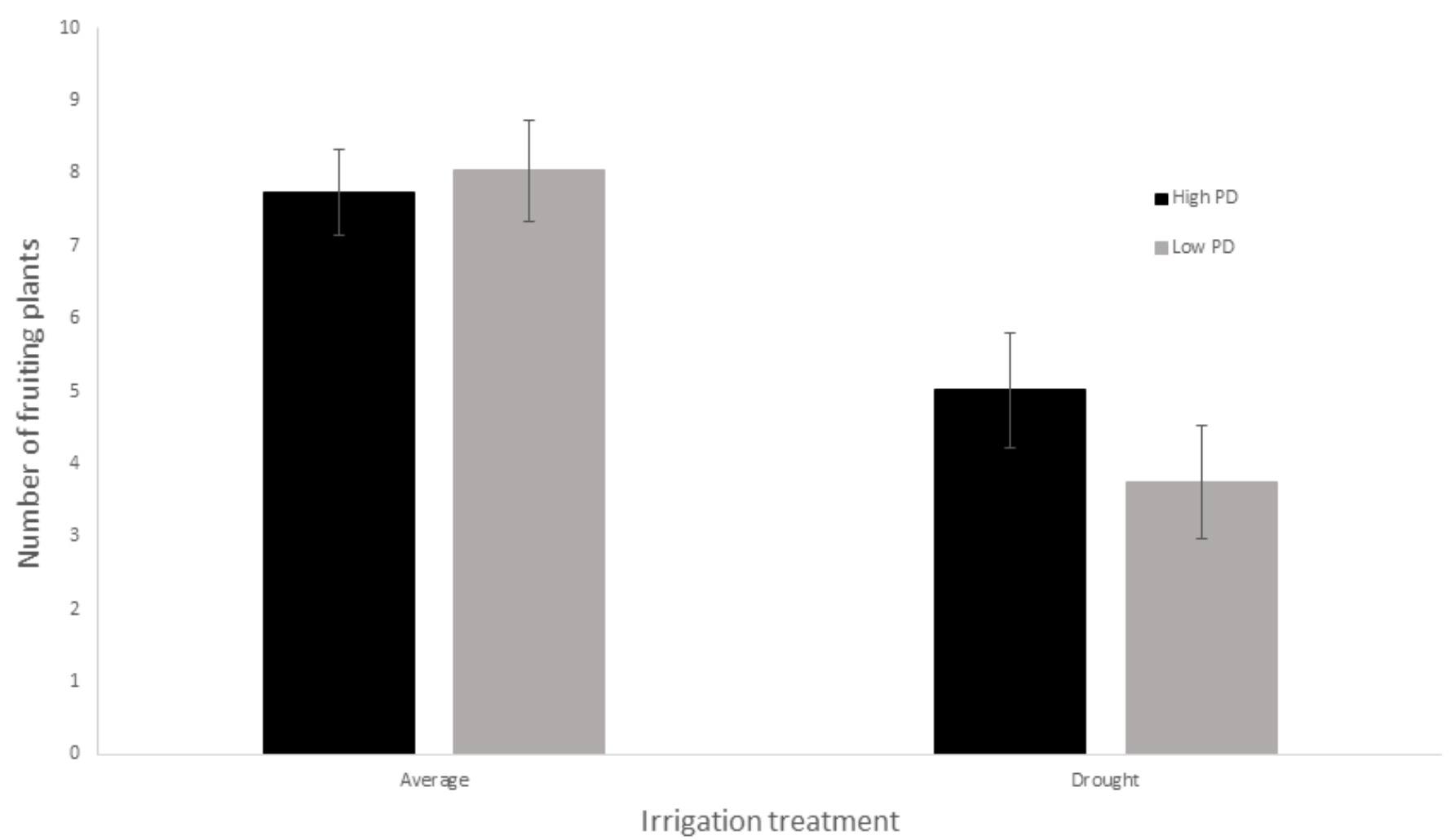

\section{Figure 3}

Average number of final fruiting plants per pot (see Table 1). Black bars represent high phylogenetic diversity scenarios and grey bars low phylogenetic diversity scenarios. Average precipitation treatments are based on natural precipitation for 30 years in the field and drought treatments represent $33 \%$ of the average precipitation. Vertical bars represent the standard error.

\section{Supplementary Files}

This is a list of supplementary files associated with this preprint. Click to download.

- SIChavesetal.docx 